\title{
Rectal bleeding and polyps
}

\author{
Thura T Latt, Richard Nicholl, P Domizio, John A Walker-Smith, Christopher B Williams
}

\begin{abstract}
Colorectal polyps are an important albeit uncommon cause of rectal bleeding in children. Colonoscopy promotes both rapid and accurate diagnosis and the opportunity for immediate therapeutic polypectomy. A 10 year audit of polyps diagnosed and treated endoscopically has been undertaken in the children's endoscopy unit. Twenty nine polyps were diagnosed from 730 colonoscopies; 24 were juvenile, two inflammatory, two PeutzJeghers, and one an adenomatous polyp.

All but one of the juvenile polyps were solitary. All children had bleeding per rectum as one of the major presenting features. About two thirds of the patients were under the age of 5 years; the mean age was 5.6 years. Most of the juvenile polyps were on the left side of the colon; $41 \%$ were distal to the sigmoid colon. However polyps were found throughout the colon, indicating that total colonoscopy is wise and rewarding in any child with persistent and intermittent rectal bleeding.
\end{abstract}

(Arch Dis Child 1993; 69: 144-147)

Rectal bleeding in children is a relatively uncommon but important complaint and an alarming event for the parents. Colorectal polyps must be considered as a possible cause ${ }^{1}$ but differential diagnosis is wide and includes anal fissure, trauma, infective enteritis, allergic enteropathy, chronic inflammatory bowel disease, Meckel's diverticulum, intestinal obstruction (intussusception), and congenital anomalies (duplication, malrotation). ${ }^{23}$ Painless intermittent fresh rectal bleeding is likely to be due to a polyp in the large bowel ${ }^{23}$ in a child who is well grown and not otherwise ill.

Fibreoptic colonoscopy and colonoscopic polypectomy are well established in adults, and the introduction of these procedures in children $^{148}$ now permits a similarly safe, effective method to investigate the entire colon, with the possibility of immediate therapeutic polypectomy. ${ }^{145910}$ The polyp can be identified and removed safely and painlessly by colonoscopic polypectomy in an appropriately sedated child during the first, diagnostic examination.

Academic Department of Paediatric

Gastroenterology,

St Bartholomew's

Hospital, West

Smithfield, London

EC1A 7BE

Thura T Latt

Richard Nicholl

P Domizio

John A Walker-Smith

Christopher B Williams

Correspondence to:

Professor Walker-Smith.

Accepted 26 February 1993 years were examined by colonoscopy for suspected chronic inflammatory bowel disease or rectal bleeding of unknown origin.

Patients were admitted on the day before colonoscopy. Preparation included full explana- tion about the procedure to the parents and patients, clear fluid diet and juices (not red coloured) for 24 hours, with senna syrup aperient $(1 \mathrm{ml} / \mathrm{kg})$ on the afternoon of admission. Picolax (Nordic; sodium picosulphate one quarter sachet for age 1-4 years, half sachet for age 4-6 years, and one sachet for age above 6 years) was given on the evening of admission and another dose was given at 5 am on the morning of colonoscopy.

Sedation and analgesia during colonoscopy included Diazemuls (Dumex; diazepam in liquid emulsion, $0.3-0.5 \mathrm{mg} / \mathrm{kg}$ ) intravenously and pethidine (1-2 $\mathrm{mg} / \mathrm{kg}$ ) intravenously given slowly over a period of 1-2 minutes while observing the patient's consciousness stage and ability to talk coherently. The antispasmodic, Buscopan (Boehringer Ingelheim; hyoscine $\mathrm{N}$-butylbromide) $20 \mathrm{mg}$ intravenously was given to produce good colonic relaxation for 5-10 minutes and was very helpful during examination of the overactive bowel for polyps and other lesions. ${ }^{45}$

Either an adult or paediatric type colonoscope was used depending on the age and size of the patient. Most adolescents and older children easily tolerated the adult size colonoscope (diameter $1.5 \mathrm{~cm}$ ). Specific paediatric colonoscopes (diameter $1.1 \mathrm{~cm}$ ) were ideal for younger children. ${ }^{11}$ At the time of colonoscopy some children experienced minor abdominal discomfort or distension. The combination of pethidine and diazepam gave satisfactory analgesia with subsequent amnesia for the procedure ${ }^{1}$ in almost all cases and general anaesthesia was not needed.

All the polyps seen were removed by snare polypectomy and specimens sent for histological examination. There were no complications during or after colonoscopic polypectomy.

\section{Results}

Altogether 730 children age ranging from 3 months to 16 years were colonoscoped during this 10 year period. Twenty nine patients were found to have colorectal polyps; $24(82 \cdot 8 \%)$ had a juvenile polyp, two $(6.9 \%)$ had an inflammatory polyp, two (6.9\%) had Peutz-Jehgers polyps, and only one (3.4\%) had an adenomatous polyp.

Details of the patients and polyps are shown in table 1. Juvenile polyps were commonest. All but one (patient 10 with three juvenile polyps; see table 1) of the juvenile polyps were solitary with equal sex distribution (12 boys and 12 girls). Sixteen children $(66.7 \%)$ were under the age of 5 years and eight (33.3\%) between 5 and 12 years. The mean age was 5.6 years; the youngest was $2 \cdot 7$ years (patient 18) and oldest 12 years (patient 11). Clinical presentation of juvenile polyps in 24 children is shown in table 2 .

In this study one patient had massive bright red rectal bleeding with pallor and hypo- 
volaemia. She was given a blood transfusion three days before colonoscopy and polypectomy.

Distribution of the juvenile polyps is shown in fig 1 . Most were found in the left colon.

\section{MICROSCOPIC APPEARANCE}

Microscopic appearances of juvenile polyp, Peutz-Jeghers polyp, adenomatous polyp, and inflammatory polyp are shown in figs $2,3,4$, and 5 respectively.

Table 1 Polyps in children (from fanuary 1982-March 1992)

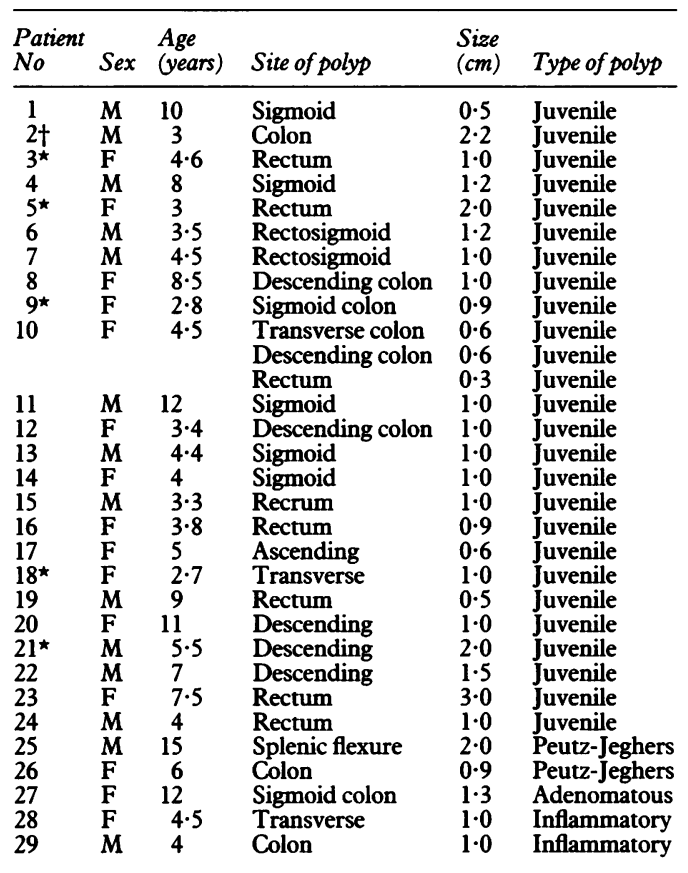

*These patients had sigmoidoscopy before colonoscopy. This patient had a polyp missed on colonoscopy.

Table 2 Clinical presentation of juvenile polyps in 24 children

\begin{tabular}{lc}
\hline Clinical features & No(\%) of children \\
\hline Intermittent fresh rectal bleeding & $24(100)$ \\
Lower abdominal pain & $9(37 \cdot 5)$ \\
Mucous in stools & $5(20 \cdot 8)$ \\
Painful defaecation & $4(16 \cdot 7)$ \\
Rectal prolapse & $3(12 \cdot 5)$ \\
Diarrhoea & $2(8 \cdot 3)$ \\
Constipation & $2(8 \cdot 3)$
\end{tabular}

Figure 1 Number of juvenile polyps and their distribution in large bowel; * 1 polyp missed on colonoscopy, supposedly in the sigmoid colon.

\section{Discussion}

Although colorectal polyps are relatively rare in children, they are an important cause of chronic and intermittent bleeding per rectum. ' Bleeding per rectum ranges from streaks of fresh blood,

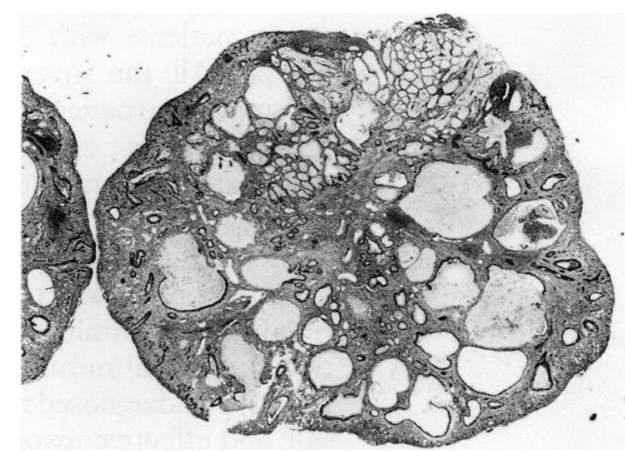

Figure 2 Low power photomicrograph of a juvenile polyp composed of cystically dilated glands and abundant stroma.

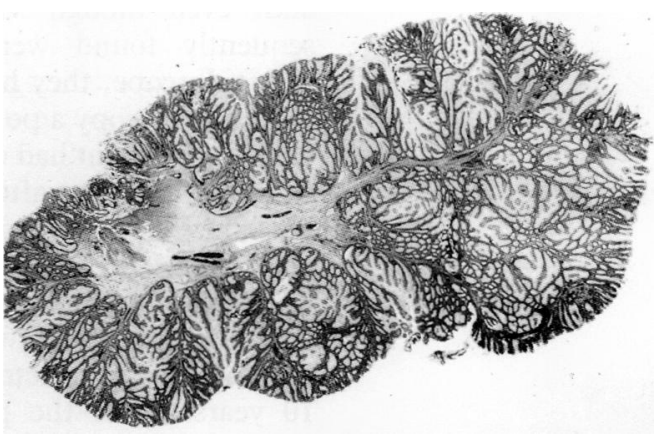

Figure 3 Low power photomicrograph of a Peutz-7eghers polyp composed of arborising strands of smooth muscle lined by colonic mucosa.

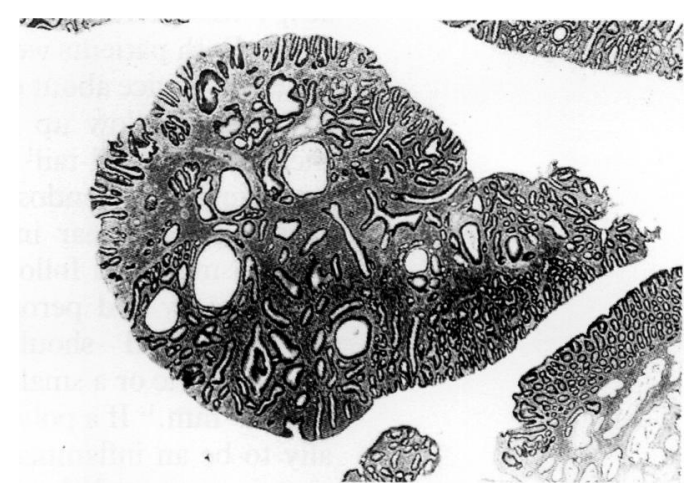

Figure 4 Low power photomicrograph of a tubular adenoma composed of tubular glands lined by mildly dysplastic epithelium.

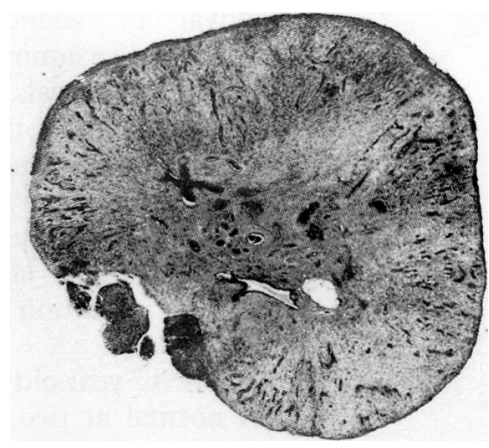

Figure 5 Low power photomicrograph of an inflammatory polyp composed of granulation tissue and occasional residual glands. 
sometimes mixed with stools, to a massive bleeding episode.

The commonest type of polyps seen in this study were juvenile polyps $(82 \cdot 8 \%)$ and almost all were on the left side of the colon (see fig 1), mostly around the rectosigmoid area, but also in the descending, transverse, and even ascending colon suggesting that total colonoscopy is essential in patients with bleeding to avoid missing polyps. All the juvenile polyps were solitary except for one patient (see table 1) who had three juvenile polyps, emphasising the need to complete examination of the whole colon even if a polyp is found.

Fibreoptic colonoscopy is the best way to diagnose polyps and permits immediate painless removal under mild sedation. This procedure is now our initial means of investigating all children with undiagnosed rectal bleeding. ${ }^{1}$ It permits safe and effective inspection of the entire colon. Five of the patients in this study had sigmoidoscopy before colonoscopy for rectal bleeding and, even though some of the polyps subsequently found were within the reach of sigmoidoscope, they had all been missed. Even with colonoscopy a polyp can be missed; in this study one patient had colonoscopy and no polyp was identified, but after two months the patient passed a $2 \cdot 2 \mathrm{~cm}$ polyp spontaneously per rectum, presumably missed at colonoscopy in the convolutions of the sigmoid colon.

No complications were seen during or after colonoscopic polypectomy in this study period of 10 years. After the procedure almost all the patients had no signs and symptoms of rectal bleeding except for two who were readmitted with similar complaints two and six years after polypectomy respectively. Repeated colonoscopy was performed but no polyps were identified. Both patients were managed with reassurance and advice about diet and bowel habit.

Planned follow up for Peutz-Jeghers polyps includes 'top and tail' endoscopy (that is upper gastrointestinal endoscopy and total colonoscopy) at two year intervals and small bowel barium meal and follow through examinations. Laparotomy and peroperative enteroscopy will be performed should the patient become symptomatic or a small bowel polyp grow larger than $15 \mathrm{~mm} .{ }^{12}$ If a polyp is confirmed histologically to be an inflammatory type further evaluation is not needed unless one of the familial syndromes is suspected.

There is substantial literature on the necessity for long term follow up of adults after removal of adenomatous polyps. Further colonoscopic examinations should be performed at two year intervals when multiple index polyps are present, and at three year intervals when the index lesion is a single adenoma and other risk factors for colonic neoplasia are not present. The identification and evaluation of patients at increased risk for colonic ademonas is likely to result in a reduction in the incidence of colorectal cancer. $^{13}$

In our 12 year old patient a check colonoscopy was normal at two years and we have recommended a long term follow up at five yearly intervals in view of the possibility of formation of further adenomas.
There is no evidence that follow up is required for children with one or two juvenile polyps. The question of follow up in children with multiple juvenile polyps is more uncertain. Juvenile polyposis, a precancerous condition requiring follow up has previously been defined as $\mathbf{1 0}$ or more juvenile polyps. ${ }^{14}$ However we have experience of malignancy developing in an adult with less than 10 juvenile polyps previously removed and would so advise repeat colonoscopy in any child with four or more juvenile polyps, perhaps every three years in the first instance. Other studies suggest that patients with juvenile polyps who have three or more juvenile polyps or a family history of juvenile polyps should undergo surveillance for colorectal neoplasia. Periodic surveillance by colonoscopy with multiple random biopsies of both polyps and flat mucosa every several years seems appropriate for these patients. ${ }^{15}$

\section{Conclusion}

Fibreoptic colonoscopy under sedation is a safe procedure in children. Colorectal polyps are a rare but important cause of rectal bleeding in children and some of these polyps, such as adenomatous polyp and Peutz-Jeghers polyps, need to be investigated with regular follow up colonoscopy to detect recurrence and early malignant changes.

Our results suggest that in certain categories of patients, such as those with unexplained rectal bleeding and suspected chronic inflammatory bowel disease, total colonoscopy is particularly rewarding..$^{16}$ Colonoscopy should be considered as a first line procedure in such patients as it is easy to establish or exclude bleeding pathology and has the advantage of biopsy and immediate polypectomy.

It is also very important that these children are investigated at a centre skilled in paediatric endoscopy and where there are facilities for expert histological review.

1 Douglas JR, Campbell CA, Salisbury DM, Walker-Smith JA, Williams CB. Colonoscopic polypectomy in children. $B M \mathcal{F}$ 1980; 281: 1386-7.

2 Walker-Smith JA, Hamilton JR, Walker WA. Gastrointestina haemorrhage. In: Walker-Smith JA, Hamilton JR, Walker WA, eds. Practical paediatric gastroenterology. London: Butterworths, 1983: 52-6.

3 Walker-Smith JA, Hamilton JR, Walker WA. Miscellaneous disorders. Walker-Smith JA, Hamilton JR, Walker WA, disorders. Walker-Smith JA, Hamilton JR, Walker WA, eds. Practical paediatic

4 Cotton PB, Williams CB. Colonoscopy. In: Cotton PD, Williams CB, eds. Practical gastrointestinal endoscopy. Oxford: Blackwell Scientific Publications, 1980: 160-223.

5 Cotton PB, Williams CB. Colonoscopic polypectomy. In: Cotton PB, Williams CB, eds. Practical gastrointestinal endoscopy. Oxford: Blackwell Scientific Publications, 1980:

6 Swarbride ET, Fevre DI, Hunt RH, Thomas BM, Williams CB. Colonoscopy for unexplained rectal bleeding. $B M \mathcal{F}$ 1978; ii: 1685-7.

7 Holgerson LO, Massberg SM, Miller RE. Colonoscopy for rectal bleeding in children. $\mathcal{F}$ Pediatr Surg 1978; 13: 83-5.

8 Cremer M, Pecters JP, Emonts P, Rodesch P, Cadranel S. Fibroendoscopy of the gastrointestinal tract in children experience with newly diagnosed fibrescopes. Endoscopy 1974; 6: 186-9.

9 Gleason WA, Goldstein PD, Schatz BA, Tedesco FJ. Colonoscopic removal of juvenile colonic polyps. $\mathcal{f}$ Pediatr Surg scopic removal of
$1975 ; 10: 519-21$.

10 Winter HS. Intestinal polyps. In: Walker WA, Durie PR, Hamilton JR, Walker-Smith JA, Watkins JB, eds. Pediatric gastrointestinal diseases. Vol 1. Philadelphia: BC Decker, 1991: 739-53. 
11 Bines JE, Winter HS. Lower endoscopy. Pediatric gastrointestinal diseases. Vol 2. In: Walker WA, Durie PR, Hamilton JR, Walker-Smith JA, Watkins JB, eds Philadelphia: BC Decker, 1991: 1257-71.

12 Spigelman AD, Phillps RKS. Case report and management in Peutz-Jeghers polyps. $\mathcal{F} R$ Soc Med 1989; 82: 681 .

13 Cohen LB, Waye JD. Treatment of colonic polyps - practical considerations. Clinics in Gastroenterology 1986; 15: 359-76.
14 Jass JR, Williams CB, Bussey HJ, Morsen BC. Juvenile polyposis - a precancerous condition. Histopathology 1988; 13: $619-30$.

15 Giardiello FM, Hamilton SR, Kern SE, et al. Colorectal neoplasm in juvenile polyposis or juvenile polyps. Arch Dis Child 1991; 66: 971-3.

16 Williams CB, Laage NJ, Campbell CA, et al. Total colonoscopy in children. Arch Dis Child 1982; 57: 49-53.

\section{Eczema and the yellow emperor}

The principles of traditional Chinese herbal therapy (TCHT) were described in the Inner Classic of the Yellow Emperor which was written by our old friend, Anonymous, between 300 and $100 \mathrm{BC}$. Two recent papers have confirmed the effectiveness of such treatment in adults (Mary Sheehan and colleagues, Lancet 1992; 340: 13-7) and children (Mary Sheehan and David Atherton, British Fournal of Dermatology 1992; 126: 179-84).

It had been noted that some patients with eczema refractory to conventional treatment had been treated by a practitioner of TCHT in London with apparent success. It is almost impossible for Western physicians to give the full Chinese treatment because that varies from patient to patient, and from time to time in the same patient, depending on the TCHT practitioner's assessment of the pulse and the tongue as well as the features of the eczema. Dr Sheehan and her colleagues therefore settled for giving the herbal medicine as recommended by a Chinese medical practitioner of TCHT for use in a typical case of the particular type of eczema studied.

Forty seven children aged 18 months to 18 years were admitted to a double blind trial over a four month period. All had extensive nonexudative atopic eczema not confined to the flexures and characterised by a diffuse morbilliform or sclarlatiniform erythema usually more marked on the trunk than the limbs, and often with mild to moderate lichenification. No topical steroids were used during the study which lasted for 20 weeks and followed a double blind, placebo controlled, crossover design. Active treatment consisted of a decoction prepared from constituents of 10 plants obtained from bona fide suppliers in China. Placebo decoctions were made to have a similar appearance, taste, and smell but from herbs not thought to benefit eczema. The children were expected to drink about $100 \mathrm{ml}$ of warm decoction freshly made each day and, surprisingly, only five of them balked at it to the extent that they failed to complete the study (three active treatment, two placebo). Five others (one active treatment, four placebo) failed to complete the study because they were given either steroid treatment for asthma or an antibiotic for skin infection.

The children were assessed every four weeks using a standardised scoring system for erythema and skin surface damage. There appeared to be clear benefit during active treatment. The median percentage decrease in scores for erythema was $51 \%(34.5$ to $72.6 \%)$ during the active treatment phases and $6 \%(-25 \cdot 2$ to $30 \cdot 7 \%)$ on placebo, and for surface damage $63 \%(34.5$ to $72 \cdot 6 \%)$ during active treatment and $6 \%$ $(-25 \cdot 2$ to $30 \cdot 7 \%)$ on placebo. Of the 37 children completing the trial 19 were reported to have slept better on active treatment and three on placebo. When asked to say which phase of treatment was better the parents of 27 children identified the active treatment phase and of two the placebo phase. In eight cases the parents were unable to choose between the two phases. No toxicity was identified during the study but the authors point out that they have no information about long term toxicity.

How it works is not known but it does not appear to be a corticosteroid-like effect. The authors are cautiously optimistic about the potential value of the treatment and, although the trial was restricted to one form of severe eczema, they say that they have 'no reason to believe' that it would not be effective in other types.

Four cheers for Dr Ding-Hui Luo for her cooperation, say I. 